\title{
A Model-Based Approach to Preplanting Risk Assessment for Gray Leaf Spot of Maize
}

\author{
P. A. Paul and G. P. Munkvold
}

First author: Department of Plant Pathology, Iowa State University, Ames 50011; and second author: Pioneer Hi-Bred International, Johnston, IA 50131.

Accepted for publication 7 August 2004.

\begin{abstract}
Paul, P. A., and Munkvold, G. P. 2004. A model-based approach to preplanting risk assessment for gray leaf spot of maize. Phytopathology 94:1350-1357.

Risk assessment models for gray leaf spot of maize, caused by Cercospora zeae-maydis, were developed using preplanting site and maize genotype data as predictors. Disease severity at the dough/dent plant growth stage was categorized into classes and used as the response variable. Logistic regression and classification and regression tree (CART) modeling approaches were used to predict severity classes as a function of planting date (PD), amount of maize soil surface residue (SR), crop-

used to validate the models. Preplanting data showed a strong relationship with late-season gray leaf spot severity classes. The most important predictors were SR, PD, GLSR, and LON. Logistic regression models correctly classified 60 to $70 \%$ of the validation cases, whereas the CART models correctly classified 57 to $77 \%$ of these cases. Cases misclassified by the CART models were mostly due to overestimation, whereas the logistic regression models tended to misclassify cases by underestimation. Both the CART and logistic regression models have potential as management decision-making tools. Early quantitative assessment of gray leaf spot risk would allow for more sound management decisions being made when warranted.
\end{abstract} ping sequence, genotype maturity and gray leaf spot resistance (GLSR) ratings, and longitude (LON). Models were development using 332 cases collected between 1998 and 2001. Thirty cases collected in 2002 were
Additional keywords: corn, disease prediction, Zea mays.
The first report of gray leaf spot of maize (Zea mays L.), caused by Cercospora zeae-maydis Tehon and Daniels, dates to 1925 when the disease was observed in Alexander County, Illinois (40). Since then, the disease has been reported in most of the maize-producing areas of the United States $(21,23,44)$ and, over the past 20 years, has become a major problem in both seed and grain maize production. The increased prevalence and severity of gray leaf spot has been attributed to an increase in the use of minimum tillage $(18,21,35,44)$. This practice favors the survival of the pathogen in the previous year's crop residue left on the soil surface $(8,32,33,43)$. Payne et al. (32) and Ward et al. (43) reported that no-tillage favored the early appearance of lesions of gray leaf spot and resulted in greater end-of-season disease severity than tillage.

Current management practices for gray leaf spot involve the use of moderately resistant hybrids, crop rotation, tillage, timely planting, and foliar application of fungicides $(29,43)$. In areas where gray leaf spot is endemic, the success of crop rotation and tillage depends on their widespread adoption, since the ingress of inoculum from nearby fields may lead to early disease development even in plots without maize residue on the soil surface (10). Tillage has been difficult to fully implement because of soil conservation practices (27). Although foliar fungicide applications have been shown to be profitable in maize production for seed (25), their use in grain maize production has been rare because the value of the yield response may not be sufficient to offset the cost of chemical control. The probability of profitable fungicide use in maize grown for grain is strongly dependent on the yield potential and susceptibility of the hybrid planted (29). This leaves

Corresponding author: P. A. Paul; E- mail address: paul.661@osu.edu

Publication no. P-2004-1011-04R

(c) 2004 The American Phytopathological Society hybrid selection as the most important tool for effective and profitable management of gray leaf spot in grain maize production.

Moderately resistant hybrids are highly recommended for gray leaf spot management. Some high-yielding hybrids are highly susceptible to this disease $(13,39)$. The decision to use a moderately resistant hybrid for gray leaf spot management is often made based on the history of gray leaf spot at the location, cropping sequence, and the type of residue management practiced. These decision-making tools provide no quantitative measure of the risk and level of gray leaf spot severity, and none of these factors used alone have been a good predictor of gray leaf spot disease severity. For example, although the amount of surface residue was shown to have a significant positive relationship with gray leaf spot severity $(5,9,37)$, other factors such as location and genotype influenced the relationship between crop residue and disease $(5,37,43)$. Sound decision-making criteria based on accurate risk assessment are needed to achieve more effective and profitable management of gray leaf spot. A preplanting risk assessment model may provide valuable information regarding the likelihood and severity of gray leaf spot in order to guide preplanting management decisions.

Gray leaf spot development is associated with preplanting variables such as maize soil surface residue, genotype resistance, and planting date (44). Gray leaf spot severity increases as the percentage of maize residue on the soil surface increases (9). Lateplanted maize generally has greater gray leaf spot severity than early-planted maize $(22,36)$. Initial infection by $C$. zeae-maydis occurs at an earlier plant growth stage on late-planted maize, allowing for more secondary cycles during the growing season $(36,44)$. The reported association between gray leaf spot onset and crop anthesis (36) suggests that disease development may also be influenced by genotype maturity. Bhatia and Munkvold (5) reported a strong east to west variation across the state of Iowa in gray leaf spot severity and the number of hours of weather 
conditions favorable for gray leaf spot development. This suggests that field location (latitude and longitude) constitutes another important preplanting factor that can be used to develop risk assessment models for gray leaf spot.

In human epidemiology, modeling approaches such as logistic regression and classification and regression tree (CART) have been used as risk assessment tools to guide the implementation of treatments $(7,15,17,24,30)$. Such methods can be applied to the field of plant pathology in order to guide disease management decisions. Tree-based models are widely used to devise prediction rules for both classification and regression problems. These approaches provide advantages over linear and additive models in that they are nonparametric and relatively easy to implement and interpret. In addition, CART models uncovered interactions among variables generally overlooked by traditional modeling approaches (30). Unlike other approaches, such as discriminant analysis commonly used to model categorical data, logistic regression and CART models make no assumption about the distribution of the predictors. There are several documented reports of the application of logistic regression and CART modeling approaches in botanical epidemiology $(11,20,28)$. De Wolf et al. (11) used binary logistic regression models to assess the risk of Fusarium head blight of wheat based on within-season weather variables. They reported prediction accuracies ranging from 62 to $85 \%$.

In this study, our objective was to use preplanting variables, previously correlated with late-season gray leaf spot severity (5), to develop CART and logistic regression-based risk assessment models that may be used to make gray leaf spot management decisions prior to planting.

\section{MATERIALS AND METHODS}

Site selection and data collection. Site history and agronomic information were collected at the beginning of the 1998, 1999, 2000, 2001, and 2002 growing seasons from commercial seed production fields, hybrid strip trials, and research plots located in 17 counties in southern Iowa (between latitudes $40^{\circ} 42^{\prime} 04^{\prime \prime} \mathrm{N}$ and $\left.42^{\circ} 12^{\prime} 60^{\prime \prime} \mathrm{N}\right)$. Data were collected from 13 sites in 1998, 11 sites in 1999, 10 sites in 2000, 11 sites in 2001, and 5 sites in 2002. These sites were chosen to represent areas with different histories of gray leaf spot, varying cropping practices, and a range of weather conditions. At each location, three to eight maize genotypes (inbreds or hybrids) with gray leaf spot resistance ratings ranging from 2 to 7 (based on a 1-to-9 rating scale, with 1 being most susceptible and 9 being most resistant) and maize maturity ranging from 98 to 119 days comparative relative maturity (CRM) were planted in 2- to 18-row plots. Rows ranged from $5 \mathrm{~m}$ to several hundred meters long and planting density varied from 64,000 to 79,000 plants per hectare. Plots were planted between 22 April and 1 July.

At each location, the latitude and longitude (degrees) were recorded using a hand-held Magellan GPS 4000 global positioning unit (Magellan Systems Corporation, San Dimas, CA). The amount of maize residue covering the soil surface was estimated using a line transect method (21) as described previously (4,5). A $16-\mathrm{m}$ measuring tape was extended diagonally across the rows of each plot and the presence or absence of maize residue was recorded at 50 consecutive points, at $0.3-\mathrm{m}$ intervals, along the tape. The total number of points with residue was multiplied by 2 to determine the percentage of soil surface covered with residue. The previous crop (maize or soybean) planted at each location was recorded and the number 1 was assigned to fields where maize was the previous crop, while 0 was assigned to fields where soybean was the previous crop. Planting dates (as day of the year), maturity, and gray leaf spot resistance ratings were also recorded for each genotype at each location. Genotype resistance and maturity ratings were based on information provided by the seed suppliers.
Each location was visited at 14-day intervals, and disease severity was assessed by visually estimating the percentage of the ear leaf covered with gray leaf spot lesions. At each assessment, 10 plants from each genotype were arbitrarily selected and gray leaf spot severity on the ear leaf was determined by using a standard area diagram as a reference (31). Gray leaf spot severity on the ear leaf at the R4/R5 plant growth stage (34) was used as the response variable for model development. This leaf position and growth stage were chosen because gray leaf spot severity at approximately this stage was reported as providing the best relationship with yield loss (19). Disease severity data were categorized to generate ordinal (more than two ordered classes) and binary response variables. For the ordinal response, five disease severity classes were created: $1=<20 \% ; 2=\geq 20$ and $<40 \% ; 3=$ $\geq 40$ and $<60 \% ; 4=\geq 60$ and $<80 \%$; and $5=\geq 80 \%$. The two classes for the binary response were $0=<20 \%$ and $1=\geq 20 \%$ disease severity. The class structure of the data was decided upon following preliminary graphical analysis of the raw data and based on critical yield loss thresholds for gray leaf spot (19). Gray leaf spot severity above $20 \%$ in the middle third of the plant at the dough/dent plant growth stage significantly impacts yield $(19,44)$ and thus constitutes an excellent threshold value for risk assessment and management decision-making.

Model development. Factors previously reported as having linear relationships with gray leaf spot severity (5) and which could be determined prior to planting were used as input variables. These included the percentage of maize residue on the soil surface (SR), planting date (PD), and genotype resistance rating (GLSR). Genotype maturity (MAT) and previous crop (PC) were also used. Since gray leaf spot severity was shown to vary considerably among locations in Iowa planted with the same genotype and having similar cropping practices, and because hours of weather conditions favorable for development of gray leaf spot were observed to have a strong east to west variation across the state (5), longitude $(\mathrm{LON})$ was also used as an input variable for model development.

Logistic regression and CART (6) were used to develop risk assessment models. Models were developed for both the ordinal and binary response variables. A total of 332 cases collected between 1998 and 2001 were used for model development. An observation with a unique combination of year, location, and values for predictor variables was defined as a case. Once fitted, the bootstrap validation (internal validation) method (12) was used to validate the models, and 30 independent cases collected in 2002 were used to assess their prediction accuracy (external validation). The independent cases were recorded using the same methods described for the data used in model development. Misclassification rates were used as a measure of model performance on the independent set of data. Sensitivity and specificity were calculated for the binary response models. Sensitivity was defined as the percentage of correctly classified cases in class 1 (severity $\geq 20 \%$ ) and specificity as the percentage of correctly classified cases in class 0 (severity $<20 \%$ ).

Logistic regression. Logistic regression models may be considered direct probability models since they are stated in terms of the probability of the occurrence of an event $(Y)$ under a given sets of conditions $(X), \operatorname{Prob}\{Y=y \mid X\}$ (15). In this study, two classes of ordinal logistic regression models, the proportional odds (PO) (26) and the continuation ratio (CR) (1) models and binary logistic regression (BLR) models, were used to model the relationship between selected preplanting variables and gray leaf spot severity classes. The PO model is based on cumulative probabilities. For a dependent variable ( $Y$, disease severity class in this case) having $k$ levels, the model is stated as

$$
P[Y \geq j \mid X]=1 / 1+e^{-\left(\alpha_{j}+X \beta\right)}
$$

where $j$ is the cutoff level of $Y, X$ is the predictor variable, and $\alpha_{j}$ and $\beta$ are intercept and regression coefficient, respectively. There 
are $k$ intercepts. For any given $j$, the model is an ordinal logistic model for $Y \geq j$ and is read as the probability of $Y \geq j$ given $X$. The $\mathrm{CR}$ model is based on conditional probabilities and is stated as

$$
P(Y=j \mid Y \geq j, X)=1 / 1+e^{-\left(\theta_{j}+X \gamma\right)}
$$

where $j$ is the cutoff level of $Y, \theta_{j}$ is the intercept, and $\gamma$ is the regression coefficient. The BLR model, stated in terms of the probability of $Y$ (disease severity class) $=1(\geq 20 \%)$, given a set of $k$ predictor variables $(X)$, is

$$
P(Y=1 \mid X)=1 / 1+e^{-X \beta}
$$

where $\beta$ is the regression parameter and $X \beta$ represents $\beta_{0}+\beta_{1} X_{1}+$ $\beta_{2} X_{2}+\ldots+\beta_{k} X_{k}$.

All models were fitted using the lrm function of the Design library (14) in S-Plus 2000 (MathSoft Inc., Seattle, WA). The modeling approach and model diagnostics were performed as described by Harrell (15), Harrell et al. (17), and Bender and Benner (3). Prior to fitting the PO and CR models, plots of the means of the predictor variables stratified by levels of the response variable were generated. These plots were overlaid with the expected values for the PO and CR models and used to check the ordinality assumption of equal slope, and the PO and CR assumptions $(3,15)$. Since the equal slope and $C R$ assumptions were violated for some of the predictor variables, an extended continuation ratio (ECR) model was fitted instead of the CR model (15). The bootstrap technique (12) was used to perform internal validation of the logistic regression models and to obtain bias-corrected estimates of prediction accuracy (16). Bias may result from overfitting the models. For all models, 1,000 bootstrap replications were used to estimate and correct for optimism in various statistical indices. Individual cases were randomly drawn with replacement from the original sample of 332 cases until a bootstrap sample of 332 cases was generated. The process was repeated for 1,000 bootstrap replications. For each replication, indices of prediction accuracy were estimated. Somers' $D_{x y}$ rank correlation (38) between predicted probabilities and observed responses was used to assess the performance of the models. $D_{x y}$ was calculated using the following equation:

$$
D_{x y}=2 \times(c-0.5)
$$

where $D_{x y}$ is the difference between concordance and discordance probabilities and $c$ is the probability of concordance between predicted probability and response. $D_{x y}$ ranges from 0 to 1 , with 0 indicating that the model was making random predictions and 1 indicating that the model was making perfect discriminations between classes.

CART. In this modeling approach, classification trees are built by using a binary partitioning algorithm to recursively split the data in each node into increasingly homogeneous subsets until the response data is pure, that is, all the cases belong to the same class. Several nonnegative functions (6) are used to determine the purity of the nodes. In the S-plus statistical package, the deviance function is used. The $S$ methodology implements classification trees as probability models (42).

The tree-based models were developed using the tree function in S-Plus 2000. The default recursive partitioning technique was used to generate dichotomous splits of the predictor variables at each node of the tree. After building trees with 14 to 23 terminal nodes, the trees were then rebuilt and pruned (removal of the least important splits) to fewer terminal nodes using the recursive partitioning (rpart) function (41). The residual mean deviance and misclassification error rates were used as a measure of goodnessof-fit of the pruned versions of the trees relative to the original trees.

\section{RESULTS}

Eighty percent of the cases collected between 1998 and 2001 were in disease severity class $1,10 \%$ in class 2 , and approximately $3 \%$ each in classes 3, 4, and 5 (Fig. 1). Gray leaf spot was most severe in 1998 and least severe in 2001. In 2001, there were no cases in classes 4 and 5. Of the 4 years, 1998 and 1999 had the highest percentage of cases in the $>80 \%$ severity class, 6 and $7 \%$, respectively.

Model development. The results of the PO and ECR ordinal logistic regression models regarding the significant effects of the predictor variables were similar. LON, SR, GLSR, and PD were highly significant predictors of disease severity classes. PC and MAT were not significant (Table 1). However, these variables were retained in the models because they were thought to provide added biological information not accounted for by the other predictor variables. In both models, LON, MAT, and GLSR had negative coefficients, whereas the coefficients for PD, PC, and SR

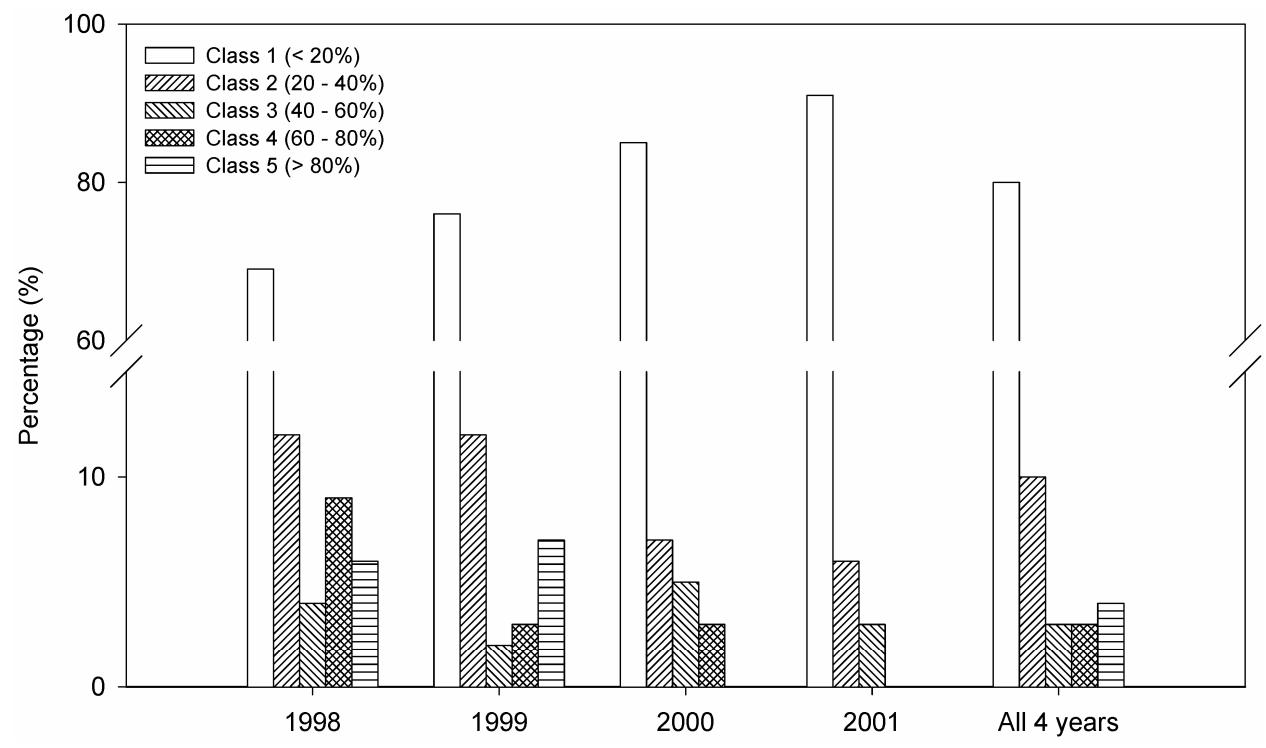

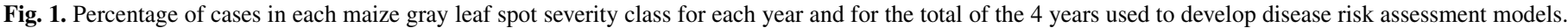

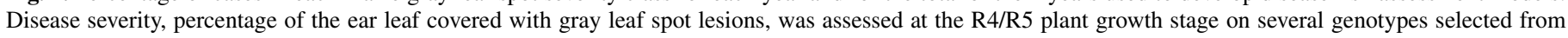
locations in southern Iowa. 
were positive. The ECR model generated slightly smaller standard errors than the PO model for all of the predictors. There was strong evidence of an association between disease severity class and both models indicated by the total $P$ values $(P<0.0001)$ and highly significant likelihood ratio (LR) $\chi^{2}$ tests (Table 1 ). The $D_{x y}$ value, an index used to measure the predictive strength of the models, was similar for both models.

From the CART model, the relationship between the input and output and the interaction between predictor variables can be perceived by starting at the top of the tree and moving down along the branches until reaching the terminal/output node (Fig. 2). The relative position of the predictors in the tree is used as a measure of their importance in predicting the outcome. LON, GLSR, SR, and PD were the most important predictors of gray leaf spot severity classes using the CART modeling approach (Fig. 2). PC and MAT were not selected. The highest risk of gray leaf spot occurred when the most susceptible hybrids (GLSR $<3$ ) were planted at sites located between longitudes $91.29 \mathrm{~W}$ and $91.41 \mathrm{~W}$ (severity of $>80 \%$ ), or at sites located east of longitude $91.29 \mathrm{~W}$ that had surface residue cover of $>60 \%$ (between 40 and $60 \%$ severity) (Fig. 2). Moderate risk (severity between 20 and 40\%) occurred when the most susceptible hybrids were planted east of longitude $91.29 \mathrm{~W}$ in fields with $<60 \%$ surface residue cover or when relatively more resistant genotypes (GLSR of $>3$ ) were planted late in the season (after day 143). For all locations west of longitude $91.41 \mathrm{~W}$, estimated disease severity was between 0 and $20 \%$. Low risk of gray leaf spot also occurred when genotypes with gray leaf spot resistant ratings of $>3$ were planted before day 143.

For the binary response variable, separation between the two classes ( $<20$ and $\geq 20 \%$ severity) was achieved with the predictor variables LON, SR, PD, GLSR, and MAT (Fig. 3). The highest degree of separation was observed for LON. In general, the ranges (indicated by the vertical bar extending from the boxes in Fig. 3) of the predictor variables were smaller for the higher severity class than for the lower class. Several BLR and CART models were developed using different combinations of these variables. Four of these models were initially selected based on their $D_{x y}$ values (Table 2). Models having LON as a predictor variable were generally superior (higher $D_{x y}$ values) to those without LON. The omission of PC and MAT from BLR1 and BLR3 resulted in simpler (BLR2 and BLR4) models with similar $D_{x y}$ values.

CART models developed for the binary response variable depicted trends similar to those observed for the ordinal response (Fig. 3), with major splits occurring at the same LON, GLSR, SR, and PD values. The omission of PC and MAT did not affect model performance; however, the omission of LON resulted in models with relatively higher residual mean deviance and misclassification error rates.

Model validation and misclassification rate. The bias-corrected indices of prediction accuracy were similar for the PO and ECR models (Table 3). For the original $D_{x y}$ values, the optimism from overfitting was estimated to be 0.02 for both models, resulting in bias-corrected estimates of predictive discrimination of 0.80 and 0.82 for the PO and ECR models, respectively. The maximum calibration error $\left(E_{\max }\right)$ was only slightly smaller for the ECR model than the PO model (Table 3). Similar indices were also generated for the best BLR models with (BLR1) and without (BLR4) LON as a predictor variable (Table 3). In general, biascorrected $D_{x y}$ values were larger for the binary logistic regression models than for the ordinal logistic regression models.

Thirty new cases were used to assess the performance of the models on an independent data set. For the ordinal response models, the highest predicted probability value was used to assign each case to a disease severity class, while for the binary response models, a probability value of $>0.5$ was used to assign cases to the class with severity of $\geq 20 \%$. For the ordinal response, CART cor-

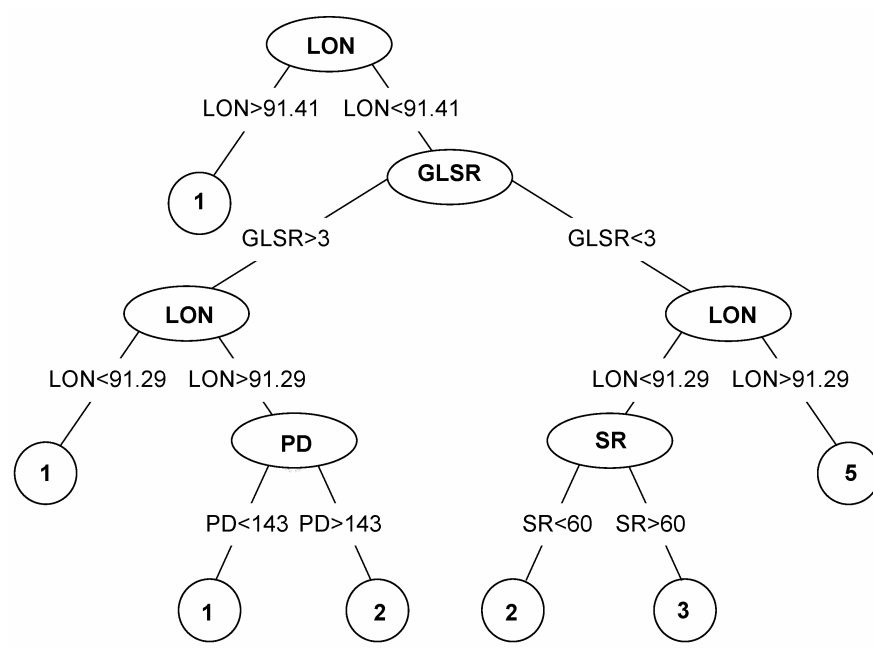

Fig. 2. Classification tree used to estimate gray leaf spot severity classes (in circles) $(1=<20 \% ; 2=\geq 20$ and $<40 \% ; 3=\geq 40$ and $<60 \% ; 4=\geq 60$ and $<80 \%$; and $5=\geq 80 \%$ ) as a function of preplanting site and genotype information collected in Iowa between 1998 and 2001. The tree was pruned to seven terminal nodes from the original 23-node tree. LON = longitude, GLSR $=$ gray leaf spot resistance ratings (based on a 1-to-9 scale: $1=$ most susceptible to $9=$ most resistant), $\mathrm{SR}=$ percentage of maize surface residue, $\mathrm{PD}=$ planting date in day of year, and MAT = genotype maturity rating in days comparative relative maturity (CRM).

TABLE 1. Estimates for the proportional odds and extended continuation ratio ordinal logistic regression models assessing the risk of gray leaf spot of maize using preplanting site and genotype data collected in Iowa between 1998 and 2001

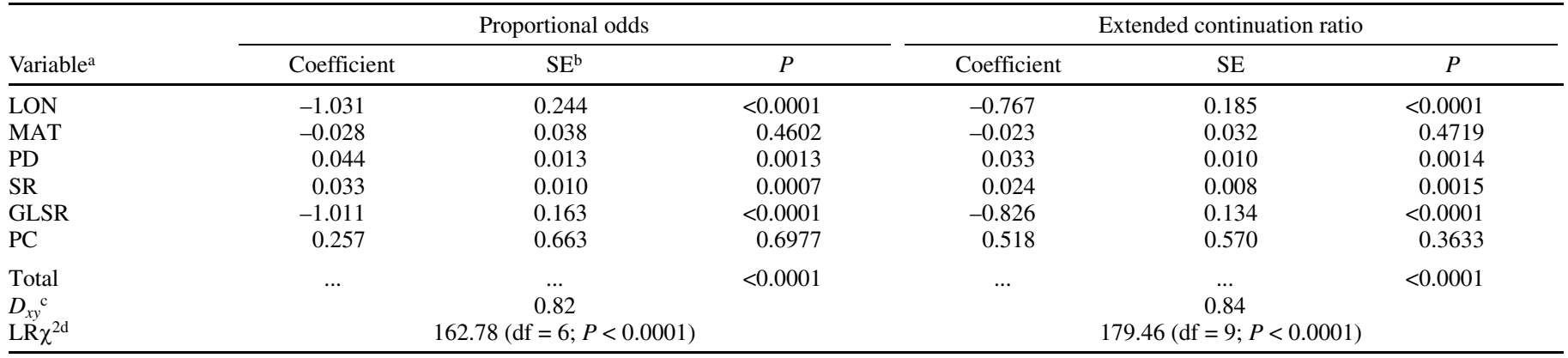

${ }^{a}$ LON $=$ longitude, GLSR = gray leaf spot resistance ratings $(1=$ most susceptible to $9=$ most resistant $), \mathrm{SR}=$ percentage surface residue, $\mathrm{PD}=$ planting date in day of year, $\mathrm{PC}=$ previous crop $(1=$ corn and $0=$ soybean $)$, and MAT $=$ genotype maturity rating in comparative relative maturity $(\mathrm{CRM})$. The response variable was gray leaf spot severity classes $(1=<20 \% ; 2=\geq 20$ and $<40 \% ; 3=\geq 40$ and $<60 \% ; 4=\geq 60$ and $<80 \%$; and $5=\geq 80 \%)$.

b Standard error.

' Somers' rank correlation between predicted probabilities and observed responses.

${ }^{d}$ Likelihood ratio $\chi^{2}$. 
rectly classified 17 of the 30 validation cases. Nine erroneous classifications were due to overestimation and four to underestimation of disease severity class. When used to estimate the probability of having disease severity of $\geq 20 \%, 76.7 \%$ of the cases were correctly classified (model CARTB, Table 4). All of the misclassifications were due to overestimation. The CARTB model correctly classified $100 \%$ of the validation cases with severity of $\geq 20 \%$ (sensitivity) and $61 \%$ of the cases with severity of $<20 \%$ (specificity). The inclusion of PC and MAT as predictor variables did not alter the prediction accuracy of this model. The PO model correctly classified $66.7 \%$ of the cases when used to predict the probability of being in one of the five ordinal classes. Similarly, the ECR model correctly classified 18 of the 30 cases. In both instances, most of the misclassified cases were predicted as being in a class lower than their actual class. The omission of PC and MAT from the PO and ECR models resulted in slightly inferior prediction accuracies (data not shown). In general, BLR models that used LON as a predictor variable had higher prediction accuracies than the BLR models developed without LON (Table 4). The BLR model with the highest prediction accuracy (BLR1) correctly classified 21 of the 30 validation cases. Three of the nine misclassified cases were due to overestimation and the other six to underestimation. Model BLR2, developed without the use of MAT and PC as predictors, had inferior prediction accuracy,
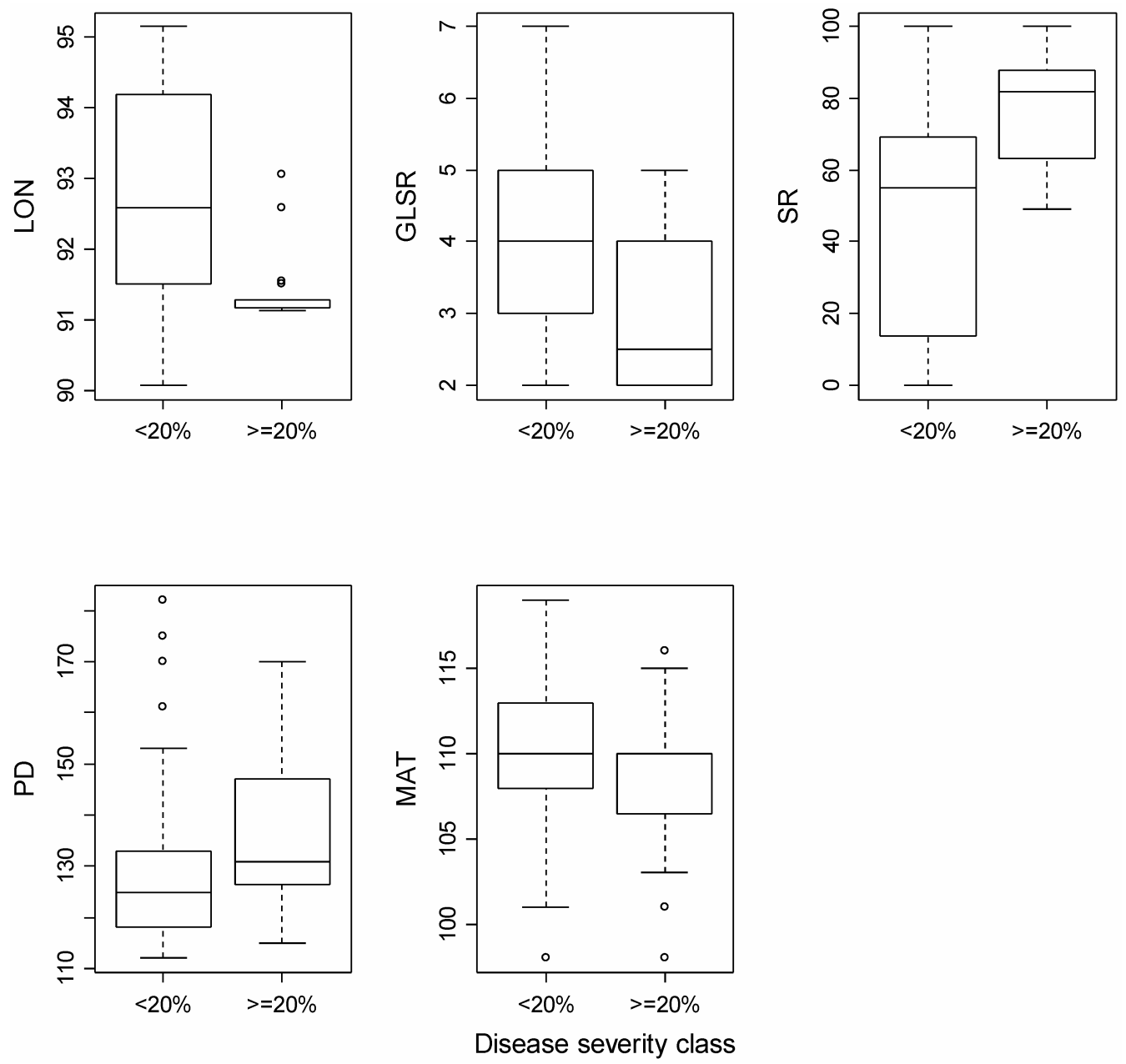

Fig. 3. Box plots summarizing the distribution of preplanting predictor variables within two gray leaf spot severity classes defined by a $20 \%$ severity threshold. The lower, inner, and upper lines of each box represent the 25th, 50th (median), and 75th percentiles of the data, respectively. Vertical bars extending beyond the boxes represent the 10th and 90th percentiles, while circles represent outliers. LON = longitude, GLSR $=$ gray leaf spot resistance ratings $(1=$ most susceptible to $9=$ most resistant), $\mathrm{SR}=$ percentage of surface residue, $\mathrm{PD}=$ planting date in day of year, and MAT = genotype maturity rating in comparative relative maturity (CRM). All data were collected in Iowa between 1998 and 2001

TABLE 2. Binary logistic regression (BLR) models developed using different combinations of preplanting site and genotype variables to predict severity classes of gray leaf spot of maize in Iowa

\begin{tabular}{llcc}
\hline Model & \multicolumn{1}{c}{ Model equation $^{\mathrm{a}}$} & $D_{x y} \mathrm{~b}^{\mathrm{b}}$ & ${\text { LR } \chi^{2} / P \text { value }^{\mathrm{c}}}$ \\
\hline BLR1 & $92.73-0.03109 \mathrm{MAT}+0.05564 \mathrm{PD}+0.1045 \mathrm{PC}+0.03753 \mathrm{SR}-1.0517 \mathrm{LON}-1.1237 \mathrm{GLSR}$ & 0.87 & $161.67 /<0.0001$ \\
BLR2 & $90.76+0.05642 \mathrm{PD}+0.03879 \mathrm{SR}-1.068 \mathrm{LON}-1.142 \mathrm{GLSR}$ & 0.87 & $161.15 /<0.0001$ \\
BLR3 & $-4.891-0.04351 \mathrm{MAT}+0.06406 \mathrm{PD}+0.7679 \mathrm{PC}+0.0432 \mathrm{SR}-1.021 \mathrm{GLSR}$ & 0.81 & $136.44 /<0.0001$ \\
BLR4 & $-9.892+0.06693 \mathrm{PD}+0.05203 \mathrm{SR}-1.051 \mathrm{GLSR}$ & 0.81 & $134.06 /<0.0001$ \\
\hline
\end{tabular}

${ }^{a}$ Binary logistic regression models developed using data collected in Iowa between 1998 and 2001. The predictor variables were LON $=$ longitude, GLSR $=$ gray leaf spot resistance ratings $(1=$ most susceptible to $9=$ most resistant $), \mathrm{SR}=$ percentage of surface residue, $\mathrm{PD}=$ planting date in day of year, $\mathrm{PC}=$ previous crop $(1=$ corn and $0=$ soybean $)$, and MAT = genotype maturity rating in comparative relative maturity $(\mathrm{CRM})$. The dependent variable was disease severity classes of $<20 \%$ (0) and $\geq 20 \%$ (1).

b Somers' rank correlation between predicted probabilities and observed responses.

${ }^{\mathrm{c}}$ Likelihood ratio $\chi^{2}$ and corresponding probability value. 
$66.7 \%$. The highest prediction accuracy for models developed without the use of LON as a predictor was $60 \%$ (model BLR4, Table 4). Relative to model BLR1, model BLR4 misclassified three more cases as having gray leaf spot severity of $<20 \%$. Both models had a specificity of $83 \%$; however, BLR1 had greater sensitivity (50\%) than BLR4 (25\%).

\section{DISCUSSION}

The importance of SR, PD, and GLSR for gray leaf spot development has been well documented in the literature $(5,9,22,32$, $33,36,43,44)$. All of the models developed in this study identified these variables as significant predictors of gray leaf spot severity, corroborating these reports, and indicating their usefulness in assessing disease risk. The late-season development of gray leaf spot and its reported dependence on plant age under field conditions (36) suggest that a late-maturing genotype may have higher levels of gray leaf spot severity at a given developmental stage than an early-maturing genotype with the same level of disease resistance. However, the results of this study indicated that MAT was not an important predictor of gray leaf spot severity, confirming previously published results (4). This may have been because the difference between the earliest- and latest-maturing genotypes was not sufficient to capture the effect of this variable. In addition, for any given location, the genotypes used in this study were planted on the same date, regardless of their maturity. This may have resulted in coincidence of anthesis, reportedly a critical stage for gray leaf spot onset and development (36), between early- and late-maturing genotypes across locations. This probably reduced the influence of plant maturity on disease development. PD probably captured the influence of favorable lateseason weather conditions better than MAT. In late-planted maize, kernel development occurs during the period when $C$. zeaemaydis activity is likely to be most favored. Coupled with infection-favorable weather conditions, spore concentration in the air increases as the season progresses $(4,33)$, allowing for more secondary cycles. There was a 70-day difference between the earliest and latest planting dates.

PC was the least important predictor. This may be attributed to the fact that it was used as an indirect measure of survival of the fungus from one season to another, a characteristic better reflected by the variable SR. For most of the locations with a soybean-maize cropping sequence, maize was rotated with soybean for only one season. Even following a maize-soybean cropping sequence, a substantial amount of maize residue still remained on the soil surface, favoring the survival of the pathogen $(8,32,33)$. The fungus survives as stromata in the substomatal cavity of diseased tissue and may remain viable for up to 1 year under field conditions (21). In areas where conservation tillage is practiced, with $30 \%$ or more residue left on the soil surface, a 1-year rotation from maize is not enough to reduce the survival of $C$. zeaemaydis (22).

The previously reported east to west variation in weather conditions across the state of Iowa (5) supports the importance of LON

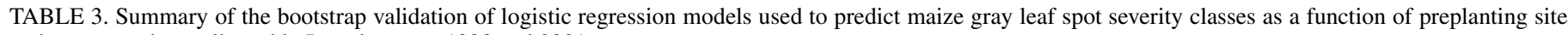
and genotype data collected in Iowa between 1998 and 2001

\begin{tabular}{|c|c|c|c|c|c|c|c|c|c|c|c|}
\hline \multirow[b]{2}{*}{ Ordinal response models } & \multicolumn{2}{|c|}{ Original } & \multicolumn{2}{|c|}{ Training $^{\mathrm{a}}$} & \multicolumn{2}{|c|}{ Testing ${ }^{\mathrm{b}}$} & \multicolumn{2}{|c|}{ Optimism $^{\mathrm{c}}$} & \multicolumn{2}{|c|}{ Corrected index } & \multirow[b]{2}{*}{$\mathrm{N}$} \\
\hline & $\mathrm{PO}^{\mathrm{d}}$ & $\mathrm{ECR}^{\mathrm{e}}$ & $\mathrm{PO}$ & ECR & $\mathrm{PO}$ & ECR & $\mathrm{PO}$ & ECR & $\mathrm{PO}$ & ECR & \\
\hline$D_{x y}^{\mathrm{f}}$ & 0.82 & 0.84 & 0.83 & 0.84 & 0.81 & 0.82 & 0.02 & 0.02 & 0.80 & 0.82 & 1,000 \\
\hline$E_{\max }^{\mathrm{g}}$ & 0.00 & 0.00 & 0.00 & 0.00 & 0.03 & 0.01 & 0.03 & 0.01 & 0.03 & 0.01 & 1,000 \\
\hline Binary response models & $\mathrm{BLR}^{\mathrm{h}}$ & BLR $4^{\text {h }}$ & BLR1 & BLR4 & BLR1 & BLR4 & BLR1 & BLR4 & BLR1 & BLR4 & $\mathrm{N}$ \\
\hline$D_{x y}$ & 0.87 & 0.81 & 0.88 & 0.82 & 0.86 & 0.81 & 0.02 & 0.01 & 0.85 & 0.81 & 1,000 \\
\hline$E_{\max }^{x y}$ & 0.00 & 0.00 & 0.00 & 0.00 & -0.05 & -0.02 & 0.05 & 0.02 & -0.05 & -0.02 & 1,000 \\
\hline
\end{tabular}

a Training refers to the performance of the models when evaluated on the bootstrap samples.

b Test refers to model accuracy when applied without modification to the original sample.

c Optimism due to overfitting refers to the difference between training and testing.

d Proportional odds logistic regression model.

e Extended continuation ratio logistic regression model.

f Somers' rank correlation between predicted probabilities and observed responses.

g Maximum absolute error in predicted probability.

${ }^{\mathrm{h}}$ Binary logistic regression models described in Table 2.

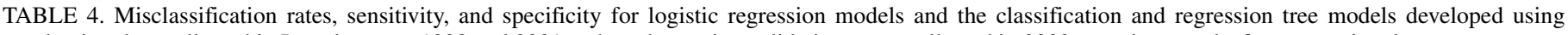
preplanting data collected in Iowa between 1998 and 2001 and used to assign validation cases collected in 2002 to maize gray leaf spot severity classes

\begin{tabular}{|c|c|c|c|c|c|c|}
\hline \multirow[b]{2}{*}{ Classification rate ${ }^{\mathrm{a}}$} & \multicolumn{3}{|c|}{ Ordinal $^{b}$} & \multicolumn{3}{|c|}{ Binary $^{c}$} \\
\hline & $\mathrm{PO}^{\mathrm{d}}$ & $\mathrm{ECR}^{\mathrm{e}}$ & CART $^{\mathrm{f}}$ & BLR19 & BLR4" & CARTB $^{\text {h }}$ \\
\hline Correct & $20 / 66.67$ & $18 / 60.00$ & $17 / 56.67$ & $21 / 70.00$ & $18 / 60.00$ & $23 / 76.66$ \\
\hline Overestimation & $2 / 6.67$ & $4 / 13.33$ & $9 / 30.00$ & $3 / 10.00$ & $3 / 10.00$ & $7 / 23.33$ \\
\hline Underestimation & $8 / 26.67$ & $8 / 26.6$ & $4 / 13.33$ & $6 / 20.00$ & $9 / 30.00$ & $0 / 0.00$ \\
\hline Sensitivity $(\%)^{\mathrm{i}}$ & $\ldots$ & $\ldots$ & $\ldots$ & 50 & 25 & 100 \\
\hline Specificity $(\%)^{\mathrm{j}}$ & $\ldots$ & $\ldots$ & $\ldots$ & 83 & 83 & 61 \\
\hline
\end{tabular}

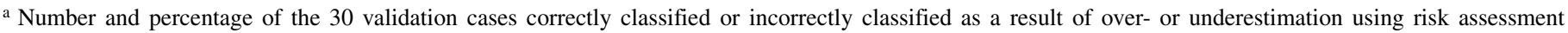
models.

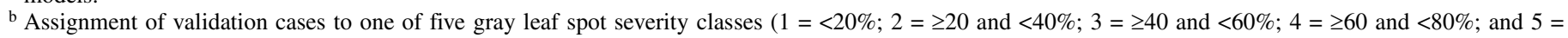
$\geq 80 \%$ ).

c Assignment of validation cases to one of two gray leaf spot severity classes $(<20 \%$ or $\geq 20 \%)$.

$\mathrm{d}$ Proportional odds ordinal logistic regression model.

e Extended continuation ratio ordinal logistic regression model.

f Tree-based model fitted to ordinal response.

g Binary logistic regression models described in Table 2.

h Tree-based model fitted to binary response date using planting date, surface residue, gray leaf spot resistance ratings, and longitude as predictors.

i Sensitivity = percentage of correctly classified cases in class $1(\geq 20 \%$ severity $)$.

j Specificity $=$ percentage of correctly classified cases in class $0(<20 \%$ severity $)$. 
as an important predictor. LON was highly significant with a negative coefficient. Bhatia and Munkvold (5) reported that the number of hours of relative humidity $(\mathrm{RH})>95 \%$ was generally higher in eastern than in western Iowa, and that locations with high disease severity had correspondingly greater number of hours of $\mathrm{RH}>95 \%$. Prolonged periods of high $\mathrm{RH}$ are known to favor the development of gray leaf spot $(2,21,36,44)$.

Logistic regression models provided strong evidence of associations with disease severity classes (total $P<0.0001$ and significant LR $\chi^{2}$ tests) (Tables 1 and 2). The bootstrap validation technique produced high indices of prediction accuracy for both binary and ordinal logistic regression models. Estimates of how well the models will perform on future cases were obtained after subtracting the optimism due to overfitting from the original $D_{x y}$ values, yielding bias-corrected $D_{x y}$ values (Tables 2 and 3). According to Harrell et al. (16), bias-corrected $D_{x y}$ values give a better estimate of the likely validation accuracy on new cases than the original values. The use of misclassification rates to assess the prediction accuracies of the models on the 30 validation cases resulted in slightly inferior prediction accuracies than suggested by the $D_{x y}$ values. This may have been due to patterns or trends present in the validation data set not captured in the 4-year data set used to develop the models.

The CART modeling approach provided an insightful diagrammatic representation of the relationship between the predictors and the outcome. The tree (Fig. 2) indicated that several different combinations of predictor variables may result in similar disease severity classes. It clearly indicated the strong influences of LON, GLSR, and SR on late-season gray leaf spot severity. In general, the highest levels of disease occurred when the most susceptible genotypes (GLSR < 3) were planted east of LON 91.41 and when SR was high. West of LON 91.41, the other predictors appeared to have a weaker relationship with final disease severity class. These results suggest that even if a susceptible genotype was planted in an area with high surface residue, gray leaf spot severity rarely exceeds $20 \%$ (class 1) in western Iowa. As discussed previously (5), this was probably due to weather conditions in the western part of the state that were less favorable to disease development. The pruned (seven terminal nodes) tree performed better than the full tree (23 terminal nodes) in predicting the outcome of the validation cases (data not shown). This was consistent with the idea that a simplified version of the tree is less likely to overfit the data, thus generalizing better than the full tree $(7,30)$.

Given the fact that only preplanting data were used to make predictions about the late-season development of gray leaf spot, a disease that may be influenced by mid-season weather conditions, both the logistic regression and CART modeling approaches performed creditably. This holds well for future application of these models as decision-making tools for the management of gray leaf spot. Indices of prediction accuracy resulting from internal validation of the logistic models (Table 3) suggested that this type of modeling approach was appropriate for assessing the risk of gray leaf spot prior to planting. The models with the highest prediction accuracy correctly classified $70 \%$ or more of the cases when used to predict the probability of attaining severity of $\geq 20 \%$ (Table 4; models BLR1 and CARTB). Model CARTB had the highest prediction accuracy $(76 \%)$ and highest level of sensitivity $(100 \%)$ (percentage of correctly classified cases with severity of $\geq 20 \%$ ). This is of particular importance because yield losses due to gray leaf spot have been reported to occur above $20 \%$ severity. Jenco (19) reported that moderate to severe epidemics of gray leaf spot (severity in the middle third of the plant between 30 and $100 \%$ ) resulted in large yield reductions. When using the CART model to predict the ordinal response, there were occasions when a given case had equal probabilities (0.33) of being assigned to two adjacent classes ( 3 and 4 ). When this happened, the model arbitrarily selected one of the two classes. This inability to adequately discriminate between classes probably explains the rela- tively inferior performance of CART in predicting the ordinal response of the validation cases. The higher percentages of correctly classified cases for models developed for binary response relative to those developed for ordinal response (Table 4) may have been due, in part, to the fact that there were fewer cases in classes 3, 4, and 5 than in classes 1 and 2 (Fig. 1). This may have affected the ability of the models to adequately represent the relationships between predictor variables and higher disease severity classes. The overall misclassification resulting from the use of the models may have been due, in part, to differences in weather conditions among locations and years during the growing season. Even though gray leaf spot severity was strongly related to preplanting data, weather conditions after planting undoubtedly influenced the final level of disease severity observed at R4/R5. These effects were not captured by the models, which were designed to employ only preplanting risk factors.

Based on their prediction accuracy, models PO, BLR1, and CARTB could be used to provide invaluable information for the management of gray leaf spot of maize. Not only could they be used to make management decisions such as hybrid selection, they could also be used to assess the consequences of having to make certain management decisions due to circumstances beyond the control of the producer. For instance, if a field is located in an area prone to gray leaf spot and where inclement weather prevents early planting, models could be consulted to assess the risk associated with these constraints when a given hybrid is planted or residue management strategy is practiced. In the case of maize seed production, inbred selection is not always an option. In order to produce seed of a given maize hybrid, specific inbreds have to be planted regardless of their level of resistance. Under this production system, risk assessment models could be used as a tool to predict, prior to tasseling, the need for fungicide application. Martinson et al. (25) suggested that since detasseling removes the upper leaves that would have otherwise contributed to grain fill, it is important to protect the ear leaf and lower leaves to ensure satisfactory yield.

Prior to being integrated into a management program for gray leaf spot, these models may need to be refitted and revalidated, especially in areas outside the region from which data were collected for their development. Given the importance of LON as a predictor variable, more data should be collected in order to identify potential gray leaf spot "hot spots" in other maize-growing states. Even though models that used LON as a predictor generally performed better on the independent data set than those without LON, all models had high internal validation prediction accuracy (indicated by the $D_{x y}$ values). Further development and validation of these models using data collected from high-disease years and locations could improve their prediction accuracy. Coupled with yield loss models, these models could be used to make economically sound management decisions for gray leaf spot of maize.

\section{ACKNOWLEDGMENTS}

This research was partially supported by Pioneer Hi-Bred Int. and the USDA North Central IPM Program. We would like to thank the following people for providing sites for the study: D. Fischer, L. Herbers, B. Liska, G. Marley, A. Sayers, K. Weuthrich, A. Woodall, T. Hall, and B. VanKooten at Pioneer Hi-Bred Int.; cooperating maize growers R. Hoksbergen, T. Greiner, K. Kay, M. Moffat, and K. Brown; K. VanDee and M. Hunt of the Iowa State University Southeast Research Farm, V. Lawson of the Iowa State University Muscatine Island Research and Demonstration Farm; M. White and M. Carlton of Iowa State University Extension; J. Shriver and A. Bhatia; and P. Dixon of the Department of Statistics at Iowa State University for helping with the statistical analyses; and P. Lipps of the Department of Plant Pathology at The Ohio State University and E. De Wolf of the Department Plant Pathology at The Pennsylvania State University for critically reviewing this manuscript. 


\section{LITERATURE CITED}

1. Armstrong, B. G., and Sloan, M. 1989. Ordinal regression models for epidemiologic data. Am. J. Epidemiol. 129:191-204.

2. Beckman, P. M., and Payne, G. A. 1983. Cultural techniques and conditions influencing growth and sporulation of Cercospora zeae-maydis and lesion development in corn. Phytopathology 73:286-289.

3. Bender, R., and Benner, A. 2000. Calculating ordinal regression models in SAS and S-plus. Biom. J. 42:677-699.

4. Bhatia, A. 2000. Relationships of weather variables and cultural factors with gray leaf spot severity on maize with emphasis on the preliminary development of a disease prediction model. MS thesis. Iowa State University, Ames.

5. Bhatia, A., and Munkvold, G. P. 2002. Relationships of environmental and cultural factors with severity of gray leaf spot in maize. Plant Dis. 86:1127-1133.

6. Breiman, L., Friedman, J. H., Olshen, R. A., and Stone, C. J. 1984. Classfication and Regression Trees. Wadsworth and Brooks/Cole, Pacific Grove, CA.

7. Crichton, N. J., Hinde, J. P., and Marchini, J. 1997. Models for diagnosing chest pain: Is CART helpful? Stat. Med. 16:717-727.

8. de Nazareno, N. R. X., Lipps, P. E., and Madden, L. V. 1992. Survival of Cercospora zeae-maydis in corn residue in Ohio. Plant Dis. 76:560-564.

9. de Nazareno, N. R. X., Lipps, P. E., and Madden, L. V. 1993. Effect of levels of corn residue on the epidemiology of gray leaf spot of corn in Ohio. Plant Dis. 77:67-70.

10. de Nazareno, N. R. X., Madden, L. V., and Lipps, P. E. 1993. Characterization of gray leaf spot epidemics of maize. J. Plant Dis. Prot. 100:410425.

11. De Wolf, E. D., Madden, L. V., and Lipps P. E. 2003. Risk assessment models for wheat Fusarium head blight epidemics based on within-season weather data. Phytopathology 93:428-435.

12. Efron, B., and Tibshirani, R. 1993. An Introduction to the Bootstrap. Chapman and Hall, New York.

13. Gorman, D., Anderson, B. M., and Abad, L. 1997. Yield loss of corn hybrids with differing levels of gray leaf spot resistance. Pages 171-182 in: Proc. 52nd Annu. Corn Sorghum Res. Conf., Chicago, IL.

14. Harrell, F. E., Jr. 1996. Design: S function for biostatistical/epidemiologic modeling, testing, estimation, validation, graphics, and prediction. StatLib. http://lib.stat.cmu.edu/s/. On-line publication 16/Dec/1996.

15. Harrell, F. E., Jr. 2001. Regression Modeling Strategies with Applications to Linear Models, Logistic Regression, and Survival Analysis. SpringerVerlag, New York.

16. Harrell, F. E., Jr., Lee, K. L., and Mark, D. B. 1996. Multivariate prognostic models: Issues in developing models, evaluating assumptions and adequacy, and measuring and reducing errors. Stat. Med. 15:361-387.

17. Harrell, F. E., Jr., Margolis, P. A., Gove, S., Mason, K. E., Mulholland, E. K., Lehmann, D., Muhe, L., Gatchalian, S., and Eichenwald, H. F. 1998. Tutorial in biostatistics: Development of a clinical prediction model for an ordinal outcome: The World Health Organization Multicentre Study of Clinical Signs and Etiological Agents of Pneumonia, Sepsis and Meningitis in Young infants. Stat. Med. 17:909-944.

18. Hilty, J. W., Hadden, C. H., and Garden, F. T. 1979. Response of maize hybrids and inbred lines to gray leaf spot disease and the effects on yield in Tennessee. Plant Dis. Rep. 63:515-518.

19. Jenco, J. H. 1995. Epidemiology of Cercospora zeae-maydis on Zea mays in Iowa. M.S. thesis, Iowa State University, Ames.

20. Kim, K. S., Taylor, S. E., Gleason, M. L., and Koehler, K. J. 2002. Model to enhance site-specific estimation of leaf wetness duration. Plant Dis. $86: 179-185$.

21. Latterell, F. M., and Rossi, A. E. 1983. Gray leaf spot of corn: A disease on the move. Plant Dis. 67:842-847.
22. Lipps, P. E. 1995. Gray leaf spot of corn. Pages 37-44 in: Proc. 7th Annu. Iowa State Univ. Integr. Crop Manage. Conf., Ames.

23. Lipps, P. E. 1998. Gray leaf spot: A global threat to corn production. APSnet Feature (May). Published online by The American Phytopathological Society, St. Paul, MN.

24. Mair, J., Smidt, J., Lechleiter, P., Dienstl, F., and Puschendorf, B. 1995. A decision tree for early diagnosis of acute myocardial infarction in nontraumatic chest pain patients at hospital admission. Chest 108:1502-1509.

25. Martinson, C. A., Wegulo, S. N., Rivera, C. J. M., and Nutter, F. W., Jr. 1995. Fungicidal spray program for seed corn production. Pages 71-79 in: Proc. 49th Annu. Corn Sorghum Res. Conf., Chicago, IL.

26. McCullagh, P. 1980. Regression models for ordinal data. J. R. Stat. Soc. B42:109-142.

27. Midwest Plan Service. 1992. Conservation tillage systems and management. Iowa State Univ. Publ. MWPS-45.

28. Mila, A. L., Carriquiry, A. L., and Yang, X. B. 2004. Logistic regression modeling of prevalence of soybean Sclerotinia stem rot in the northcentral region of the United States. Phytopathology 94:102-110.

29. Munkvold, G. P., Martinson, C. A., Shriver, J. M., and Dixon, P. M. 2001. Probabilities for profitable fungicide use against gray leaf spot in hybrid maize. Phytopathology 91:477-484.

30. Nelson, L. M., Bloch, D. A., Longstreth, W. T., Jr., and Shi, H. 1998. Recursive partitioning for the identification of disease risk subgroups: A case-control study of subarachnoid hemorrhage. J. Clin. Epidemiol. 51:199-209.

31. Nutter, F. W., Jr., and Litwiller, D. 1998. A computer program to generate standard area diagrams to aid raters in assessing disease severity. (Abstr.) Phytopathology 88(suppl.):S117.

32. Payne, G. A., Duncan, H. E., and Adkins, C. R. 1987. Influence of tillage on development of gray leaf spot and number of airborne conidia of Cercospora zeae-maydis. Plant Dis. 71:329-332.

33. Payne, G. A., and Waldron, J. K. 1983. Overwintering and spore release of Cercospora zeae-maydis in corn debris in North Carolina. Plant Dis. 67:87-89.

34. Ritchie, S. W., Hanway, J. J., and Benson, G. O. 1992. How a corn plant develops. Iowa State Univ. Coop. Ext. Serv. Spec. Rep. No. 48.

35. Roane, C. W., Harrison, R. I., and Genter, C. F. 1974. Observations on gray leaf spot of maize in Virginia. Plant Dis. Rep. 58:456-459.

36. Rupe, J. C., Siegel, M. R., and Hartman, J. R. 1982. Influence of environment and plant maturity on gray leaf spot of corn caused by Cercospora zeae-maydis. Phytopathology 72:1587-1591.

37. Smith, K. L. 1989. Epidemiology of gray leaf spot of field corn (Zea mays L.) caused by Cercospora zeae-maydis Tehon \& Daniels. Ph.D. diss. University of Maryland, College Park.

38. Somers, R. H. 1962. A new asymmetric measure of association for ordinal variables. Am. Sociol. Rev. 6:799-811.

39. Stromberg, E. L., and Donahue, P. J. 1986. Hybrid performance and yield losses associated with gray leaf spot disease. Pages 92-104 in: Proc. 41st Annu. Corn Sorghum Res. Conf., Washington, DC.

40. Tehon, L. R., and Daniels, E. 1925. Notes on parasitic fungi of Illinois. Mycologia 17:240-249.

41. Therneau, T. M., and Atkinson, E. J. 1997. An introduction to recursive partitioning using the RPART routines. On-line publication. Technical Report Series No. 61. Department of Health Science Research, Mayo Clinic, Rochester, MN.

42. Venables, W. N., and Ripley, B. D. 1999. Modern Applied Statistics with S-Plus. 3rd ed. Springer-Verlag, New York.

43. Ward, J. M. J., Laing, M. D., and Cairns, A. L. P. 1997. Management practices to reduce gray leaf spot of maize. Crop Sci. 37:1257-1262.

44. Ward, J. M. J., Stromberg, E. L., Nowell, D. C., and Nutter, F. W., Jr. 1999. Gray leaf spot: A disease of global importance in maize production. Plant Dis. 83:884-895. 